\title{
Simulation model of single structured tower hybrid wind and tidal energy cultivation based on Yemen's south west coast
}

\author{
Sadeq M. Alfakih ${ }^{1,2 *}$, Tian $\mathrm{De}^{l}$, Syed Jawad Ali Shah ${ }^{l}$, Aneeq ${ }^{l}$ And Khuram Hayat ${ }^{1}$ \\ ${ }^{1}$ North china Electric Power University Beijing (NCEPU) 102206, China \\ ${ }^{2}$ Technical Industrial Institute (T.I.I) Dhamar, Yemen
}

\begin{abstract}
This paper propose the single structured tower with hybrid renewable energy cultivation on south west coast of Yemen by the means of tidal turbine which uses ocean current under the ocean and at the top of tower is wind turbine to harvest the maximum available energy resources at the same site. This single structured turbine is an efficient and cost effective way to utilize the renewable resources available at the case study area of Yemen. The meteorological analysis is also considered to increase the efficiency of this renewable energy unit as well as the Matlab simulation of generation unit is being carried out to observe the behavior of renewable sources (wind, tide current) on turbine.
\end{abstract}

\section{Introduction}

Tides are caused by the gravitational forces exerted by the sun, moon and the rotation of the earth. Tidal plants can only be installed along coast line, coasts often experience high and low tides on daily basis. The difference on water levels must be at least 5-meter-high to produce electricity. In Figure 1. Tidal energy can be cultivated from several tidal technologies like tidal barrage, tidal fences and tidal turbines.
TIDAL BARRAGES

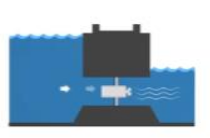

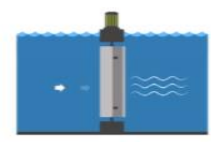

TIDAL FENCES

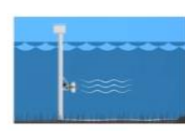

TIDAL TURBINES
Fig. 1. Tidal cultivation technology.

Tidal barrages are the most efficient tidal source; the tidal barrage is a dam which produces electricity by the change in the level of water on both sides of turbine. Tidal fences are giant turn's tiles, and the tidal turbine is the similar as the wind turbine but only in water. Ocean current can generate more energy than wind because the ocean water is 832 times denser than the air and therefore applies grater force on the turbines. Tidal powers are easy to install and renewable having no direct gashouse emission and low environmental impact. Because ocean energy is well understood, it makes tidal energy a more predictable energy source, highly attractive for electrical grid management.

swan sea in UK and the placed the large tides inside to spine the huge turbines and creating huge amounts of energy that generates enough power for 155 thousand homes per year. The tide goes in and out 4 times a day to generate electricity. The water The project costs about 1.6 billion dollars and takes 4 years to build [1].

In South Korea on Sihwa Lake $254 \mathrm{MW}$ of tidal power The tidal barrage makes use of sea wall for the flood mitigation and agricultural purposes, but soon after completion of the seawall the water became useless for agriculture and also had put bad environmental impacts on sea life [2]. The total cost of that project was about USD 560 million. However, this paper is the case study of coast of Yemen, in $2^{\text {nd }}$ section meteorological data is presented and in section 3 matlab simulation and its results are discussed.

\section{Meteorology reports on wind and tidal behaviour of study area Yemen}

Each ocean has its own system of ocean current, as the current reaches the higher latitude, they move across the ocean and turn toward the equator, washing the western margin of the continent. The current of Indian Ocean is different from those Atlantic and pacific oceans mainly because of enclosed nature of the sea and influence of the monsoon wind. In the northern part of the Indian Ocean the direction of current changes according to the season see in Figure 2.

It's being observed by the Meteorologist that the ocean warm current flow from equator towards the colder region to both poles and the cold current flow from poles to equator and turned into warm currents [3]. In Figure 4. The winds at south western coast of Yemen is at huge amount and also feasible for the implementation of wind turbines and tidal turbines together for the maximum cultivation of Energy. Figure 3 show wind speed meteorology data.

* Corresponding author: sadeqchina@gmail.com 


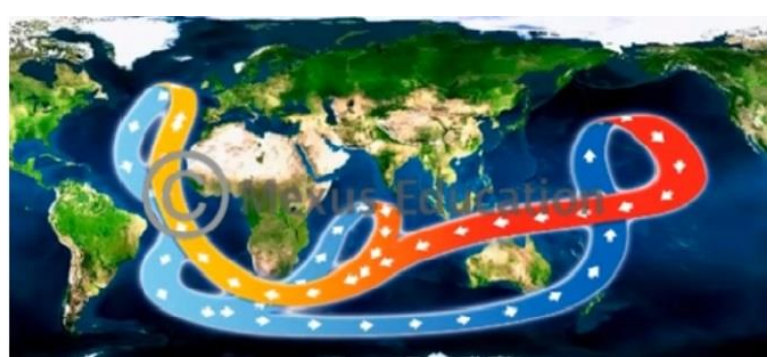

Fig. 2. Current flow in ocean.

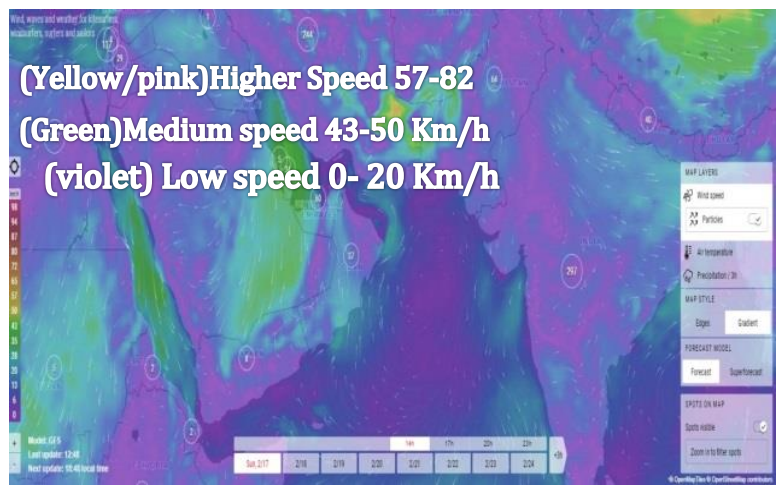

Fig. 3. Wind speed meteorology data.

\section{Mathematical modulation of ocean currents and wind turbine}

\subsection{Tide analysis}

This Model assumes that tidal elevation is represented by the summation of harmonic components, each component being represented by an oscillation at a known frequency of astronomical origin. The equation for the water level elevation in [4] is given as:

$H(t)=h_{0}+\sum_{j}^{m} f_{j} h_{j} \cos \left(w_{t} t+u_{j}-K_{j}\right)$

Where $\mathrm{H}(\mathrm{t})$ is the predicted water level depth, $f_{j}$ is the lunar node factor, $H_{j}$ is the mean amplitude, $h_{j}$ is the mean water level, $w_{t}, u_{j}, K_{j}$ represents the frequency, nodal phase and phase angle respectively for the $J_{t h}$ tidal constituents, and $\mathrm{m}$ is the number of constituents. The harmonic Model is being obtained by adding more frequencies into one function to form a stream of harmonics.

$V(t)=\sum A_{i} \operatorname{Sin}\left(2 \pi f_{i} t+\theta_{i}\right)$

Where $\mathrm{V}(\mathrm{t})$ is the tidal current speed with respect to time, $A_{i}$ is the amplitude for the $I_{t h}$ harmonic constituent, $f_{i}$ is the frequency for the $i_{t h}$ harmonic constituent, and $\theta_{i}$ is the phase angle for the $i_{t h}$ harmonic constituents [5].

\subsection{Rotor module}

The power to be generated is dependent on the plant/turbine design [6]. In tidal energy conversion system, the available power is dependent on the speed of the tidal current and the diameter of the rotor. The amount of power available in a free flow of water is given by [7]:
$P_{a v t}=\frac{\delta * A_{r} * V^{3}}{2}$

Where $P_{a v t}$ is the seawater density constant $=1025$ $A_{r}=$ Rotor blade area and $\mathrm{V}=$ Tidal current velocity

$P_{a v t}=C_{p}\left(\Lambda_{j} \theta\right) * \frac{\delta * A_{r} * V^{3}}{2}$

Where $P_{a v t}$ is the power coefficient, $\Lambda_{j}$ is the tip speed ratio and $\theta$ is the turbine blade pitch angle, the model has been designed by observing the transient simulations from other tidal energy location already in operation. By introducing saturation in its design, the power generated from the turbine is capped at a set limit for optimal operation [8][9].

\subsection{Wind turbine analysis}

The kinetic energy (in joules) in air of mass m moving with velocity $V_{w}$ (wind) can be calculated from equation (5)

$E=\frac{1}{2} m v^{2}$

The actual mechanical power $\mathrm{Pw}$ extracted by the rotor blades in watts is the difference between the upstream and the downstream wind powers

$\mathrm{P}_{w}=1 / 2 \rho \mathrm{A}_{v} V_{w}\left(V_{u}^{2}-V_{d}^{2}\right)$

$\lambda=$ blade tip speed/ wind speed

blade tip speed $=$ angular speed of turbine $(\omega) \times$ $\mathrm{R}$ wind speed

Where $\mathrm{R}$ is the radius of the turbine and $\omega$ is measured in radian per second. Air density $\rho$ is another flow input quantity at the rotor system. In [8] $\rho$ is a function of both air pressure and temperature. When air pressure increases $\rho$ increases. When air temperature decreases $\rho$ increases.

$$
P=\rho R T
$$

Where $\mathrm{R}$ is the gas constant. Both temperature and pressure decrease with increasing elevation. Hence site location is important as elevation has major effect on power generated as a result of air density variation. At atmospheric pressure, Patm $=14.7 \mathrm{psi}$, temperature is $\mathrm{T}=$ $600 \mathrm{~F}$ and density is $\rho=1.225 \mathrm{~kg} / \mathrm{m} 3$. Temperature and pressure both vary with elevation. This affects the air density.

\section{Architectural structure of hybrid tower}

The tidal turbines are installed in under water level with twin 16 meter rotor to capture the kinetic flow of the tide current, 180 degree pitch control to generate power from flood and ebb tide providing predictable runtime of 20 hours a day and 1.2 MW of clean energy can be harvested for 1500 homes The advantage of this technology lies in the high density of water: Relatively small underwater rotors can be used to generate the same amount of 
electricity as larger wind turbines on land and sea at the same time[10]. At the top of tower, the 1.5 MW of generator is being functioning to capture the wind stream.

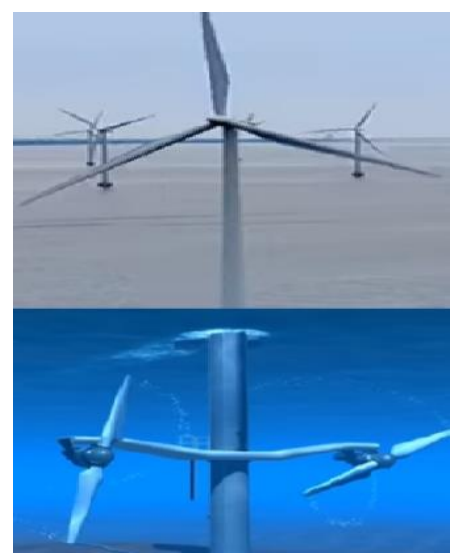

Fig. 4. Structure of Hybrid turbine Tower.

\section{Simulation model}

This model in Figure 5 contains two constraints for the simulation one for tidal energy and other for wind. The tidal energy is being analyzed by giving a stream of frequencies applied as input source of turbine to behave like a tide. the combination of two systems are showed and in Figure 6 the tidal generation unit power.

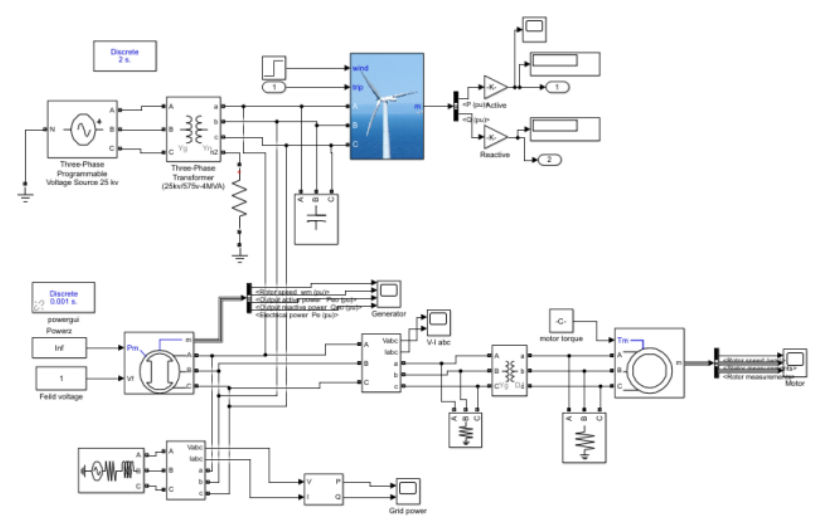

Fig. 5. Simulink model.

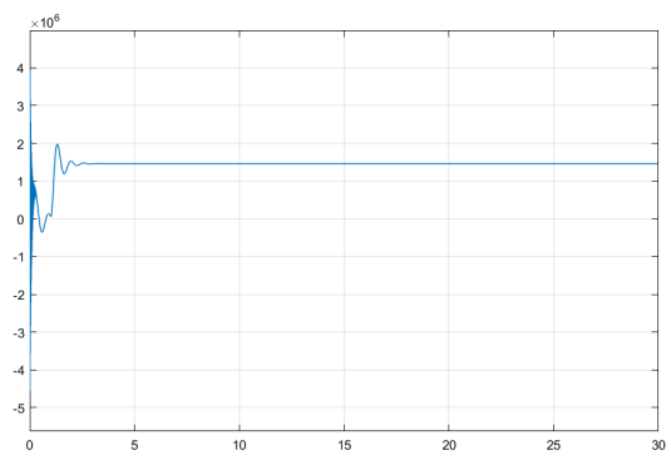

Fig. 6. Tidal generation unit power.

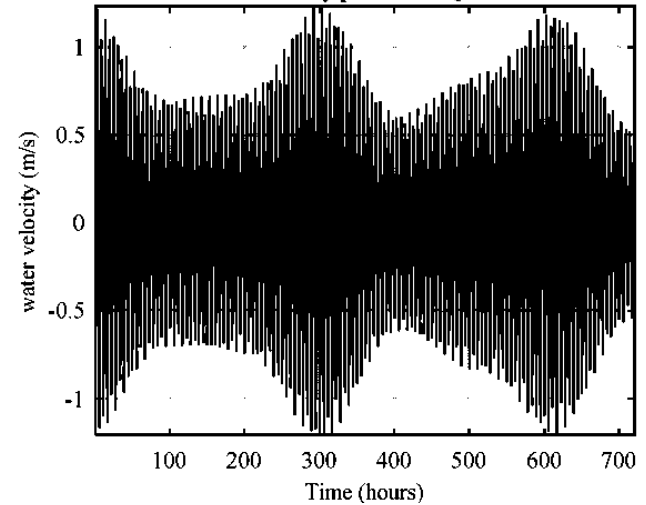

Fig. 7. wind turbine output power.

Figure 7 shows the wind turbine output power, the simulation of the tidal current velocity profile for 30 days. The velocity amplitude is seen to be in the range of $1.15 \mathrm{~m} / \mathrm{s}$. The simulation shows a high predictable rate of the tides and therefore, the energy expected at every given time can be obtained. In Figure 8 is rotor speed vs wind speed the initial pickup performance of tidal turbine is comparatively low because it takes some time to get in form with the tidal current and afterwards turbine reaches its maximum generation capacity.
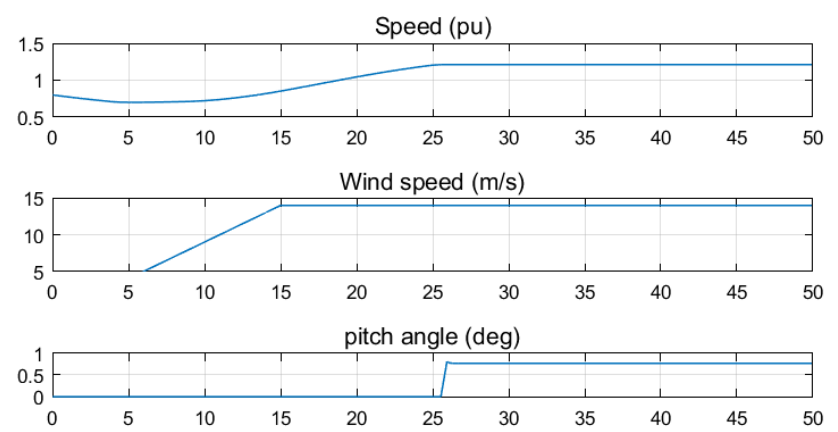

Fig. 8. Rotor speed vs wind speed.

\section{Ecological factor}

From past decades the tidal turbines are being used with various techniques to ensure reduced pollution and environmental impact. In sihwa Lake South Korea, they had implemented the barrage type of tidal plant, initially they suffered from polluting the ocean and fish run and flood but soon they regain the control over the pollution and reduced environmental risk to very low level [11][12]. The type of turbine and technique used can put a great impact on environmental changes so these tidal turbines are as much efficient for the control of pollution under the ocean as well as in air.

\section{Result discussion}

After the empirical studies and analysis, the implementation of tidal and wind turbine to the single tower make it feasible to produce enough energy and also 
reduces the cost of installation of base structure. However, we can also harvest the wind and tidal energy at the same coast. the concern study area has a potential for the implementation of that project as the tides flow from south west of Yemen and take a cycle to return back to the equator. The Electrical parameter of the tidal and wind has been examined which gives a flexible and feasible outputs compared to the different behavior and speed of tide current and wind.

\section{Conclusion}

In this paper the Matlab Simulation of tidal and wind turbine are bilaterally modeled to enhance the energy harvesting from both tide currents of ocean and wind at the coastal side of southwest Yemen. It's being observed by the meteorologist data that the tide and winds flow are higher than eastern part. As combination to two modules will reduce the cost and space and also promotes green energy production with very low ecological impact to the ocean life. 1.2 MW of tidal turbines are implemented to capture the tide current of ocean and 1.5 MW of wind turbine is being installed to cultivate the wind energy. Results obtained from the tide analysis shows that maximum flood and ebb velocities are in the range of 0.6$1.15 \mathrm{~m} / \mathrm{s}$ and $0.7-1.14 \mathrm{~m} / \mathrm{s}$ respectively which combined can produces $2.5 \mathrm{MW}$ of power for almost 3000 homes.

\section{References}

1. International Renewable Energy Agency (IRENA). June 2014. p. 36. Retrieved 12 November 2015.

2. http://www.voanews.com/a/tidal-energy...

3. Journal of International Development and Cooperation. 17 (3): 29-44.

4. Conference on Decision and Control and the European Control Conference, Seville, Spain, December 12-15 2005.

5. R. Alejandro, L. Alvaro, G. V' ' azquez, D. Aguilar and G. Azevedo, Modeling of a Variable Wind Speed Turbine with a Permanent Magnet Synchronous Generator. IEEE Inter. Symposium on Industrial Electronics (ISIE), Seoul, Korea July 5-8, 2009.

6. Tidal current energy in the Minas Passage, Bay of Fundy", Proceedings of the Institution of Mechanical Engineers, Part A: Journal of Power and Energy 222, no. 5, 493-507, 2008.

7. Nohyoung Park (May 2007) Sihwa Tidal Power Plant: a success of environment and energy policy in Korea, Korea University, www.eer.wustl.edu, retrieved 30 May 2016.

8. Rostkowski P1, Yamashita N, So IM, Taniyasu S, Lam PK, Falandysz J, Lee KT,Kim SK, Khim JS, Im $\mathrm{SH}$, Newsted JL,

9. Jones PD, Kannan K, Giesy JP (September 2006).

10. tidal current energy in the Minas Passage, Bay of Fundy", Proceedings of the Institution of Mechanical
Engineers, Part A: Journal of Power and Energy 222, no. 5, 493-507, 2008.

11. Nohyoung Park (May 2007) Sihwa Tidal Power Plant: a success of environment and energy policy in Korea, Korea University, www.eer.wustl.edu, retrieved 30 May 2016.

12. Rostkowski P1, Yamashita N, So IM, Taniyasu S, Lam PK, Falandysz J, Lee KT, Kim SK, Khim JS, Im SH, Newsted JL, Jones PD, Kannan K, Giesy JP (September 2006). "Perfluorinated compounds in streams of the Shihwa industrial zone and Lake Shihwa, South Korea". Environ. Toxicol. Chem. 25 (9): 2374-80. 